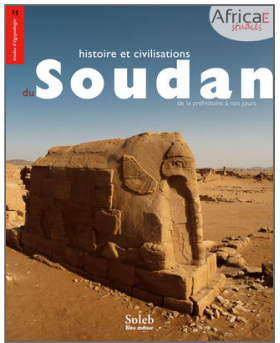

Histoire et civilisation du Soudan

De la préhistoire à nos jours

\title{
4. Le royaume du Darfour
}

\section{Bernard François}

DOI : 10.4000/books.africae.2902

Éditeur : Africae, Soleb, Bleu autour

Lieu d'édition : Paris, Khartoum

Année d'édition : 2017

Date de mise en ligne : 17 janvier 2022

Collection : Africae Studies

EAN électronique : 9782493207074

\section{OpenEdition}

\section{Books}

http://books.openedition.org

\section{Référence électronique}

FRANÇOIS, Bernard. 4. Le royaume du Darfour In : Histoire et civilisation du Soudan : De la préhistoire à nos jours [en ligne]. Paris, Khartoum : Africae, 2017 (généré le 28 janvier 2022). Disponible sur Internet <http://books.openedition.org/africae/2902>. ISBN : 9782493207074. DOI : https://doi.org/10.4000/ books.africae. 2902 
le royaume du Darfour 

jusqu'au XIX ${ }^{e}$ siècle. Le britannique W. G. Browne est le premier à situer correctement le pays, qu'il gagne depuis Assiout en 1793 et où il passera trois années. Le Darfour, suzerain du Kordofan, est à cette époque considéré comme le royaume le plus riche et le plus puissant du Soudan. Il correspond avec l'Empire ottoman et avec Bonaparte aussi, qui, victorieux des Mamelouks en Égypte, reçoit en 1799 cette lettre du sultan Abd-el-Rahman : "Nous avons l'honneur de vous informer que le bruit de vos victoires est parvenu jusqu'à nous, et nous avons appris avec joie vos conquêtes sur les Mameluks [...].» Le 12 Messidor an 7, Bonaparte passera commande au sultan de deux mille esclaves noirs.

Le pays est également connu par la remarquable narration du Shaykh Mohamed Ibn Omar el-Tounsy, publiée en français par le Dr Jomard en 1845. Le Darfour apparaissait alors comme un pays impénétrable. Chaque année, au mois du Ramadan, les caravanes fouriennes arrivaient à Assiout, avec les pèlerins, pour y écouler dents d'éléphants, esclaves, tamarin, gomme arabique, plumes d'autruche... Le $\mathrm{D}^{\mathrm{r}}$ Cuny, explorateur lorrain, y pénètre, lui, en 1858 et y disparaît dans des conditions jamais élucidées.

En 1821, après la chute du Kordofan, les forces turco-égyptiennes envisagèrent la conquête du Darfour à la suite des problèmes survenus au Sennar. En 1843, Méhémet Ali ordonna la constitution d'une puissante armée pour l'invasion du Darfour, mais l'opération fut annulée au dernier moment car Méhémet Ali soupçonnait Ahmed Pacha de trahison, tant sa popularité (voir supra p. 562) était grande.

En 1874, le sultan du Darfour et ses deux fils sont tués, et le pays

est livré aux Égyptiens, suite aux combats avec Zubair Rahmat. Ce simple représentant d'une maison de commerce devint un commerçant prospère et finalement un roi sans couronne qui possédait un palais, une armée de chasseurs d'esclaves, des zéribas le long du Haut-Nil, des arsenaux et une fortune immense. Le khédive avait élevé Zubair au rang de pacha du Bahr el-Ghazal et du Sud Darfour et l'avait chargé de compléter la conquête du Darfour, en collaboration avec Ayub Pacha. Zubair ne se contenta pas du titre de pacha mais revendiqua le titre de gouverneur général de la nouvelle province. Il décida de partir pour Le Caire pour défendre sa requête auprès du vice-roi, après avoir chargé son fils Souleymane de le remplacer pendant son absence, mais il fut retenu au en Égypte sous des prétextes divers, et devint prisonnier des faveurs du khédive.

En 1879, Romolo Gessi, nommé gouverneur du Bahr el-Ghazal par Gordon, brise la révolte du fils de Zubair, qui meurt dans les combats. Lautrichien Rudolf von Slatin est nommé par Gordon gouverneur du Darfour en 1883. Quand les troupes mahdistes se rapprochent du Darfour, 


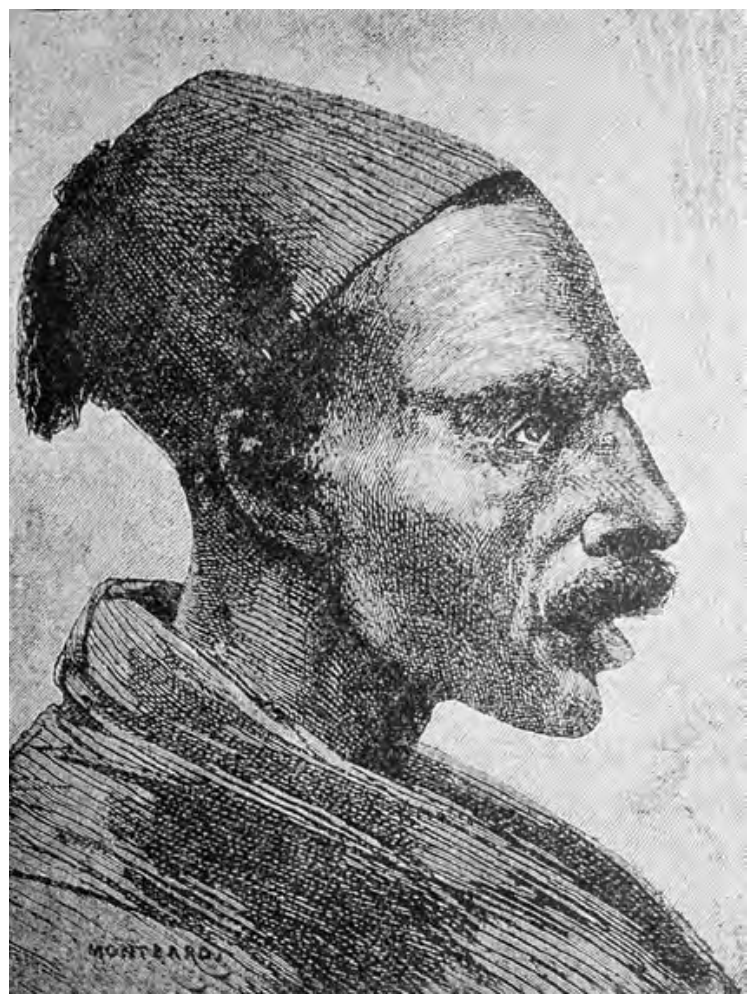

Zubair Pacha.

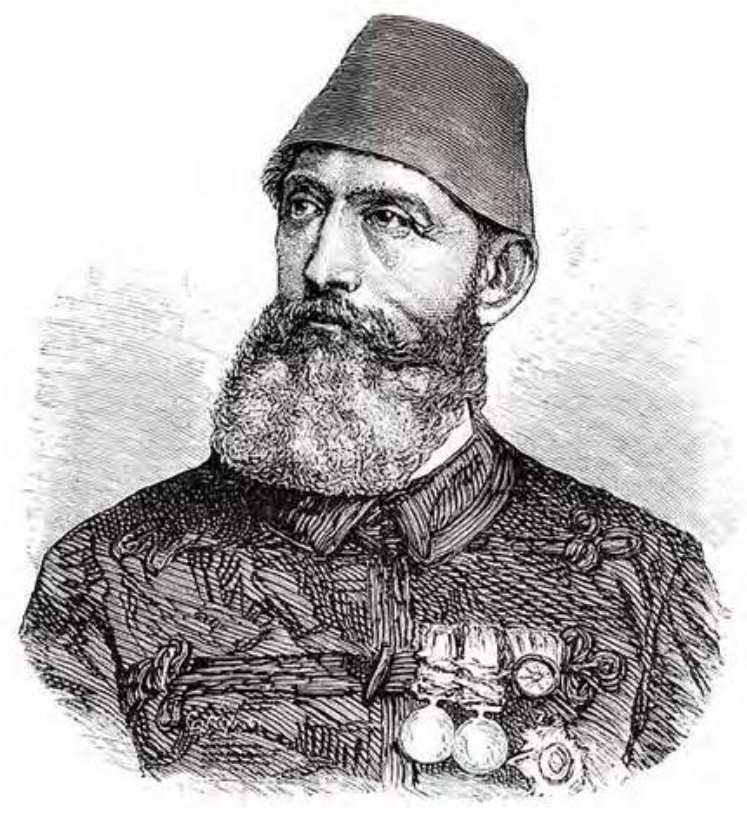

Romolo Gessi.

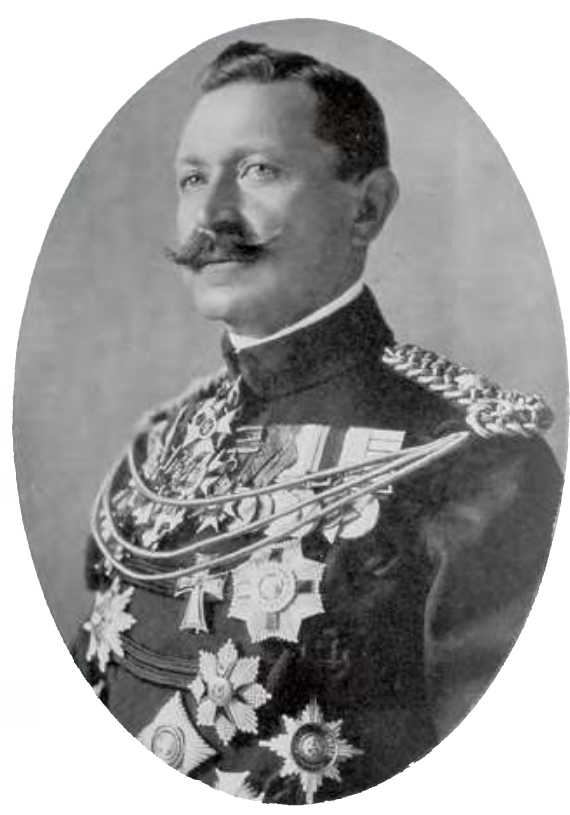

RudolfVon Slatin.

le royaume du Darfour 


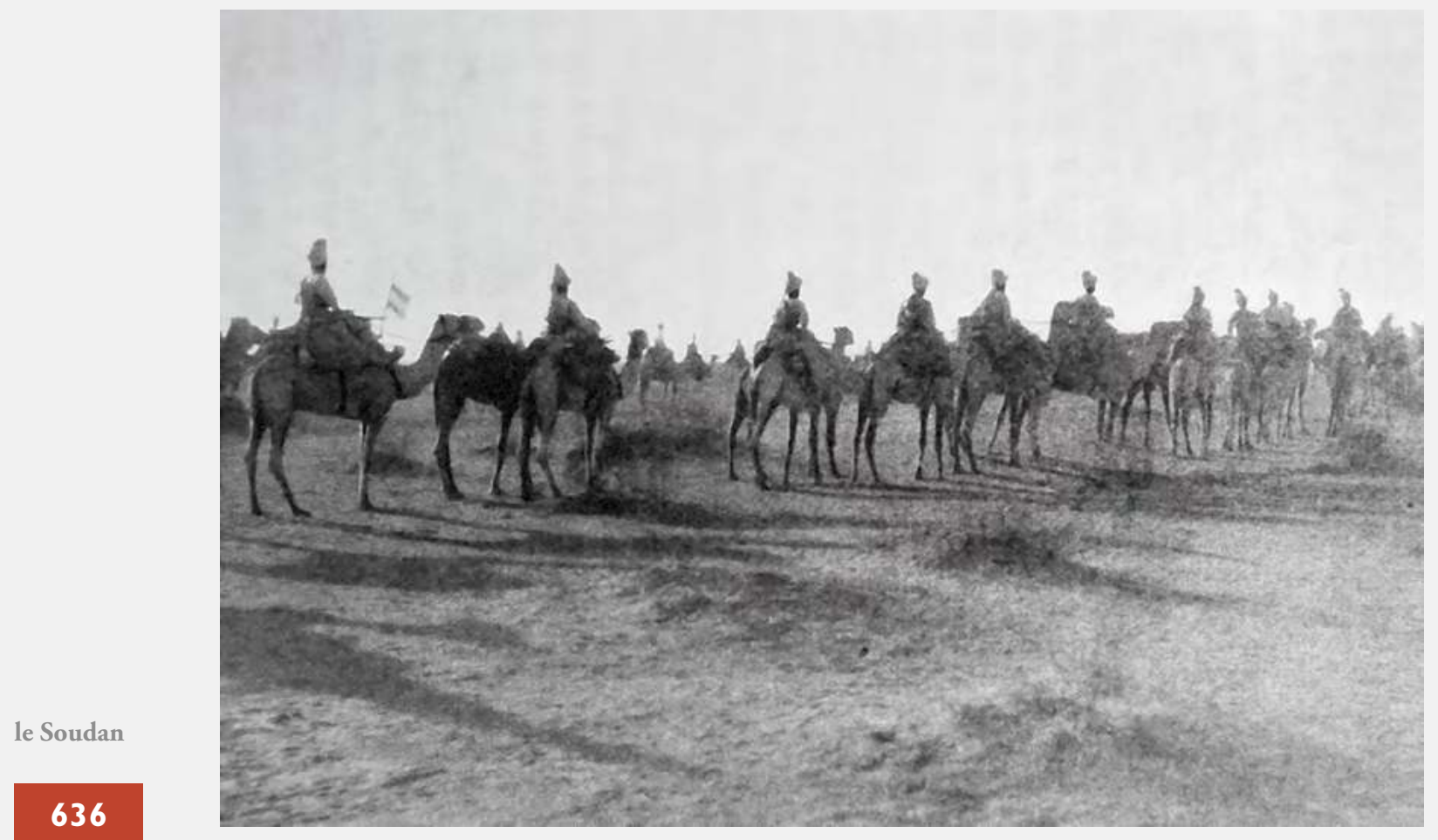

de 1820

à nos jours
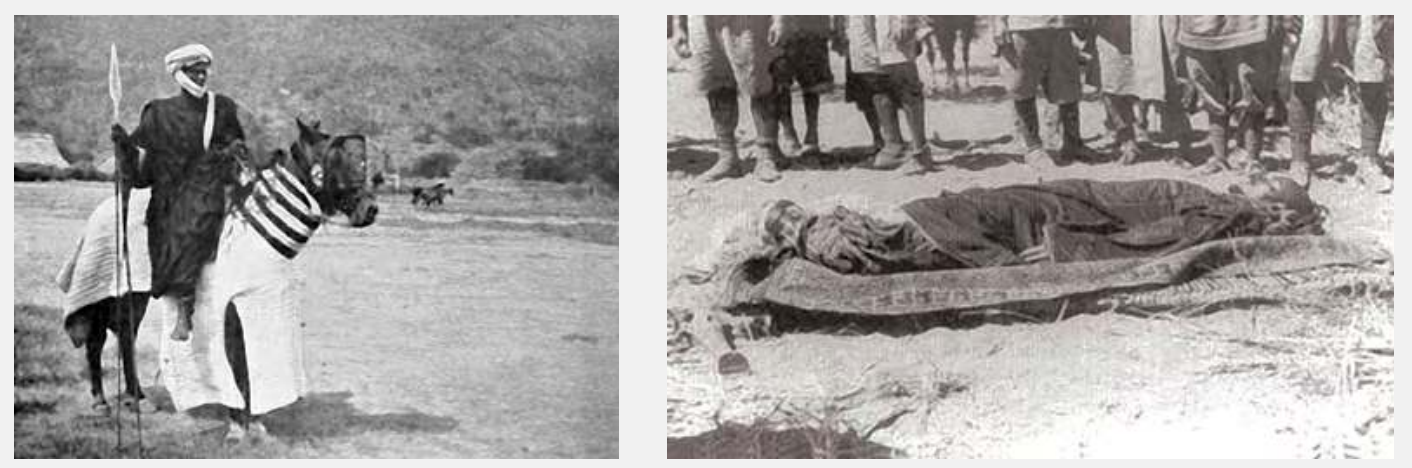

Le Camel Corps en patrouille.

Cavalier Darfuri.

Le corps d'Ali Dinar. 
il enregistre des défections massives au sein des siennes — ce qui l'empêche de livrer combat - et il se voit contraint de présenter sa reddition aux envahisseurs. Il se convertira à l'islam pour avoir la vie sauve et restera prisonnier des mahdistes à Khartoum, jusqu’à son évasion en 1895.

Le Khalifa Abdullahi, succédant au Mahdi, reprend en 1889 le contrôle du Darfour où les Fours tentaient de réinstaurer leur sultanat.

Profitant du vide du pouvoir entrainé par la fin de la période mahdiste en 1898, le sultan Ali Dinar s'installe comme maître au Darfour et lui rend son indépendance. Le nouveau régime du condominium reconnaît le sultan comme souverain du Darfour, moyennant le payement d'un tribut à Khartoum.

Mais à l'amorce de la Première Guerre mondiale qui voit la Turquie soutenir l'Allemagne, les Britanniques s'emparent de l'Égypte. Le sultan Ali Dinar, coincé entre les possessions françaises du Tchad et le Soudan contrôlé par les Britanniques, déclare le jihad contre les infidèles européens et s'associe à la tariqa sénoussiste de Libye. En mai 1916, le major Kelly entre dans el-Fasher et défait Ali Dinar.

L'armée britannique arme les Arabes du Nord, voisins, pour qu'ils effectuent des missions de reconnaissance au Darfour, mais les services de renseignement britanniques devront reconnaitre plus tard que ces groupes étaient incontrôlables: leur conception vigoureuse des « reconnaissances» les amenait à des centaines de kilomètres, pour se venger d'anciens rivaux dont ils pillaient les villages, razziaient les animaux et massacraient les proches. Ali Dinar, lui, s'est échappé, mais il est rattrapé six mois plus tard et est exécuté.

Le Darfour devient une province soudanaise, qui restera consciente de son identité propre, comme en témoigne l'histoire récente.

Après la Première Guerre mondiale, un accord passé entre les Français et les Anglais délimite la frontière occidentale du Soudan qui suivra désormais la ligne de partage des eaux entre les bassins du Nil et du Tchad. La France restitue au Soudan le Dar Massalit, partiellement conquis en 1911 et, en janvier 1924, les sultanats du Dar Tama et du Dar Sila retournent au Tchad $\mathrm{E}$ 